\title{
FINAL REPORT FOR THE DOE/ARM PROJECT TITLED \\ Representation of the Microphysical and Radiative Properties of Ice Clouds in SCMs and GCMs
}

\author{
David L. Mitchell, W. Patrick Arnott and Vanda Grubisic \\ Atmospheric Sciences Center, Desert Research Institute \\ University of Nevada System, Reno, Nevada
}

This is the final report for the Department of Energy's Atmospheric and Radiation Measurement (ARM) Program for the grant DE-FG03-00ER62935. The goal of this project was (1) to characterize the ice particle size distribution as a function of temperature and ice water content (IWC) for mid-latitude and tropical anvil cirrus clouds; (2) to predict the ice mass sedimentation rates for these cirrus clouds; (3) to test and possibly improve upon a treatment of ice cloud radiative properties, developed during the previous ARM project. Once realized, these accomplishments would provide Global Climate Models (GCMs) with accurate parameterizations regarding ice cloud size distributions, ice sedimentation rates and radiative properties. This would be done in such a way that the treatments for ice particle size distributions (PSD), fall velocities and optical properties would use the same analytical formalism. For example, a gamma distribution was used for characterizing the PSD and predicting the sedimentation rates and radiative properties; the sedimentation and radiation schemes relate ice particle mass and projected area to ice particle maximum dimension using power-law expressions. This allows the cloud optical properties to be fully coupled with the cloud microphysics; something never achieved before. That is, both the fall velocities (and ice sedimentation scheme) and optical properties are explicitly formulated in terms of a bimodal PSD and any given combination of ice particle shape in each mode of the bimodal PSD. By reducing the cloud microphysics to an effective radius or diameter $\left(D_{e}\right)$, large errors can result in both the fall velocities and optical properties. This shortcoming was avoided through the approach taken here.

In addition to these three central tasks, collaborative activities involving other institutions are reported.

\section{Parameterizing the PSD for mid-latitude cirrus clouds}

A total of 1,039 PSD, mostly from ARM IOPs, were analyzed to develop a PSD parameterization for mid-latitude cirrus clouds that were not generated by deep convection (i.e. thunderstorms). Like previous studies, we used the 2DC optical probe measurements to characterize the PSD for ice particles greater than about 50 microns. Unlike previous efforts, we used the Forward Scattering Spectrometer Probe (FSSP) to measure the concentrations and sizes of small ice crystals less than 45 microns. This was justified from comparisons between the FSSP and a new instrument known as the "Cloudscope" (developed at DRI). The operating principle of the Cloudscope is inertial impaction of ice crystals upon a $3 \mathrm{~mm}$ lens, yielding very high collision efficiencies and accurate estimates of ice crystal concentration at small crystal sizes (i.e. between 3 and 45 microns). The drawback is that the task of determining the PSD from Cloudscope video images of ice crystals is extremely labor intensive. The operating 
principle of the FSSP is the forward scattering of laser light by the cloud particle. Prior to this project, most researchers were reluctant or not willing to use the FSSP in measuring PSD from ice clouds due to the fact that the translation of the forward scattering into PSD estimates relied on Mie theory, which was valid only for spheres. But since the forward scattering depends mainly on the particle's projected area, which is expressed via the FSSP electronics as an areaequivalent sphere, errors might not be too severe. Moreover, small ice crystals measured by the FSSP tend to be spherical or quasi-spherical (Lawson et al. 2005). The major advantage of the FSSP is that it counts and sizes 1000's of particles per second electronically in real time.

Hence it represents a breakthrough in our ability to measure the ice cloud PSD if the FSSP can be used to provide reasonable estimates of the PSD for $\mathrm{D}<45$ microns $(\mathrm{D}=$ maximum ice particle dimension). We compared the FSSP with the Cloudscope during an ARM IOP and also in a laboratory cloud chamber for (1) hexagonal column and (2) hexagonal plate ice crystals. In each comparison, favorable agreement was found between the FSSP and Cloudscope PSD (Ivanova et al. 2001). While more research is needed, these findings indicate that under most conditions typical of cirrus clouds, the FSSP may measure size and concentration within a factor of 2 in general. Thus it is far better to use the FSSP measurements than to ignore them, as peak FSSP concentrations are typically 2-3 orders of magnitude greater than peak 2DC concentrations. As we will see, the FSSP PSD may dominate cirrus cloud radiative properties.

Given these results, we decided to use the FSSP to characterize the PSD for small ice crystals ( $\mathrm{D}<45$ microns). We then screened these FSSP PSD for possible errors by parameterizing this PSD, requiring that this parameterized PSD must intersect either the 1st or 2nd usable bin of the 2DC probe (i.e. in the size range of 50-100 $\mu \mathrm{m}$ ). This parameterized FSSP spectrum conserves the ice water content (IWC) and the mean and median mass dimension of the PSD, yielding a good fit to the 1st, 2 nd and $3 \mathrm{rd}$ moments of the PSD. Thus the extrapolation from $\mathrm{D} \approx 45 \mu \mathrm{m}$ (FSSP maximum size) to $\mathrm{D} \approx 75 \mu \mathrm{m}$ (of the $2 \mathrm{DC}$ ) is physically based and reasonable in our view. FSSP spectra not meeting this criteria were eliminated from the analysis. This resulted in reducing the above total by only 7\% (giving 966 PSD), which we feel, given the number of PSD analyzed, is strong evidence that FSSP PSD are reasonably continuous with 2DC size spectra. Testing for continuity has been recommended as a means for determining the validity of FSSP data (Gayet et al. 1996). Our PSD parameterization scheme was based only on these screened spectra and the 2DC spectra.

The results of this study revealed that PSD in mid-latitude cirrus clouds consist of two distinct modes; one for $\mathrm{D}<100$ microns and another for larger ice particles. Peak ice crystal concentrations in the small crystal mode are typically 2-3 orders of magnitude greater than peak concentrations in the large particle mode. These bimodal PSD were parameterized as a function of cloud temperature and IWC. As temperature increases, the amplitude of the small mode increases relative to the large mode amplitude, and vice versa. This suggests that ice crystal nucleation rates in cirrus clouds are greater near cloud base $\left(-20\right.$ to $\left.-25^{\circ} \mathrm{C}\right)$ than near cloud top, which is not what current theory would predict. These results are reported in Ivanova et al. (2001). 


\section{Parameterizing the PSD for tropical anvil cirrus clouds}

The PSD in tropical anvil cirrus clouds has been parameterized using the same methodology used to parameterize the PSD in mid-latitude cirrus clouds. Dr. Greg McFarquhar has provided us with the 2DC and FSSP data from the Central Equatorial Pacific Experiment (CEPEX), consisting of three microphysical sampling missions in three different cirrus anvil clouds. Each cloud was profiled in constant temperature legs from top-to-bottom, with each vertical profile consisting of 5 to 7 legs. The PSD used in the analysis were sampled over a 10 second interval (same as with the mid-latitude cirrus PSD), resulting in a total of 5,546 PSDs for the three case studies. Cloud temperatures ranged from $-15^{\circ} \mathrm{C}$ to $-65^{\circ} \mathrm{C}$, and mean PSD were determined for each mission for each $5^{\circ} \mathrm{C}$ temperature interval defined over this range. The large particle mode conformed well to an exponential PSD form, and the large mode PSD slope parameter $\lambda(\lambda=$ $1 / \overline{\mathrm{D}} ; \overline{\mathrm{D}}=$ mean maximum dimension $=$ mean $\mathrm{D}$ ) was related to cloud temperature with $\mathrm{a}$ correlation coefficient of $-0.941\left(r^{2}=0.885\right)$ :

$$
\overline{\mathrm{D}}=332.6 \exp (0.0335 \mathrm{~T})
$$

where $\overline{\mathrm{D}}$ is in microns and T is in deg. C. Although individual PSD can show considerable scatter at a given temperature, binning the PSD over fixed temperature intervals reveals this strong relationship between $\overline{\mathrm{D}}$ and temperature.

Analogous to the mid-latitude treatment, the IWC was partitioned between the two PSD modes in terms of $\overline{\mathrm{D}}$ :

$$
\begin{aligned}
& F_{\text {IWC }}=0.04\left(1-D_{\text {IWC }}\right)+D_{\text {IWC }}, \\
& D_{\text {IWC }}=\exp \left[-(\bar{D} / 55)^{3.7}\right],
\end{aligned}
$$

where $\mathrm{F}_{\mathrm{IWC}}=\mathrm{IWC}$ fraction in small mode and $\overline{\mathrm{D}}$ is in microns. The large mode IWC fraction is simply $1-\mathrm{F}_{\text {IWC. }}$ The actual IWC in each mode is determined by multiplying the total IWC by the respective mode fraction. As in Ivanova et al. (2001), the bimodal PSD was parameterized as two gamma distributions having the form

$$
\mathrm{N}(\mathrm{D})=\mathrm{N}_{\mathrm{o}} \mathrm{D}^{v} \exp (-\lambda \mathrm{D}) .
$$

For the small crystal mode,

$$
\overline{\mathrm{D}}=8 \times 10^{-6} \mathrm{~T}+0.0021,
$$

where $\mathrm{T}$ is $\operatorname{deg}$. $\mathrm{C}$ and $\overline{\mathrm{D}}$ is in cm units, and $v=4.02 \pm 1.38$ (the relatively small standard deviation allows us to approximate $v$ as constant). For the large mode, $v=0$. Slope parameter $\lambda$ and the parameter $\mathrm{N}_{\mathrm{o}}$ are related to $\overline{\mathrm{D}}$ and IWC, respectively, as described in Ivanova et al. (2001). 


\section{Comparison of mid-latitude and tropical anvil PSD schemes}

Examples of the PSD schemes for mid-latitude and tropical anvil cirrus clouds are shown below in Fig. 1. The key difference is that for the tropical anvil scheme, the small mode increases in amplitude with decreasing temperature $\mathrm{T}$, while the opposite occurs for the midlatitude scheme. This behavior produces dramatic differences at cold temperatures $\left(\mathrm{T}<-55^{\circ} \mathrm{C}\right)$ in the radiative properties of tropical anvil and mid-latitude cirrus clouds, as shown in Fig. 2. Since the small mode dominates the PSD projected area at cold temperatures in tropical anvil cirrus but not in mid-latitude cirrus, their radiative properties are quite different at cold temperatures.
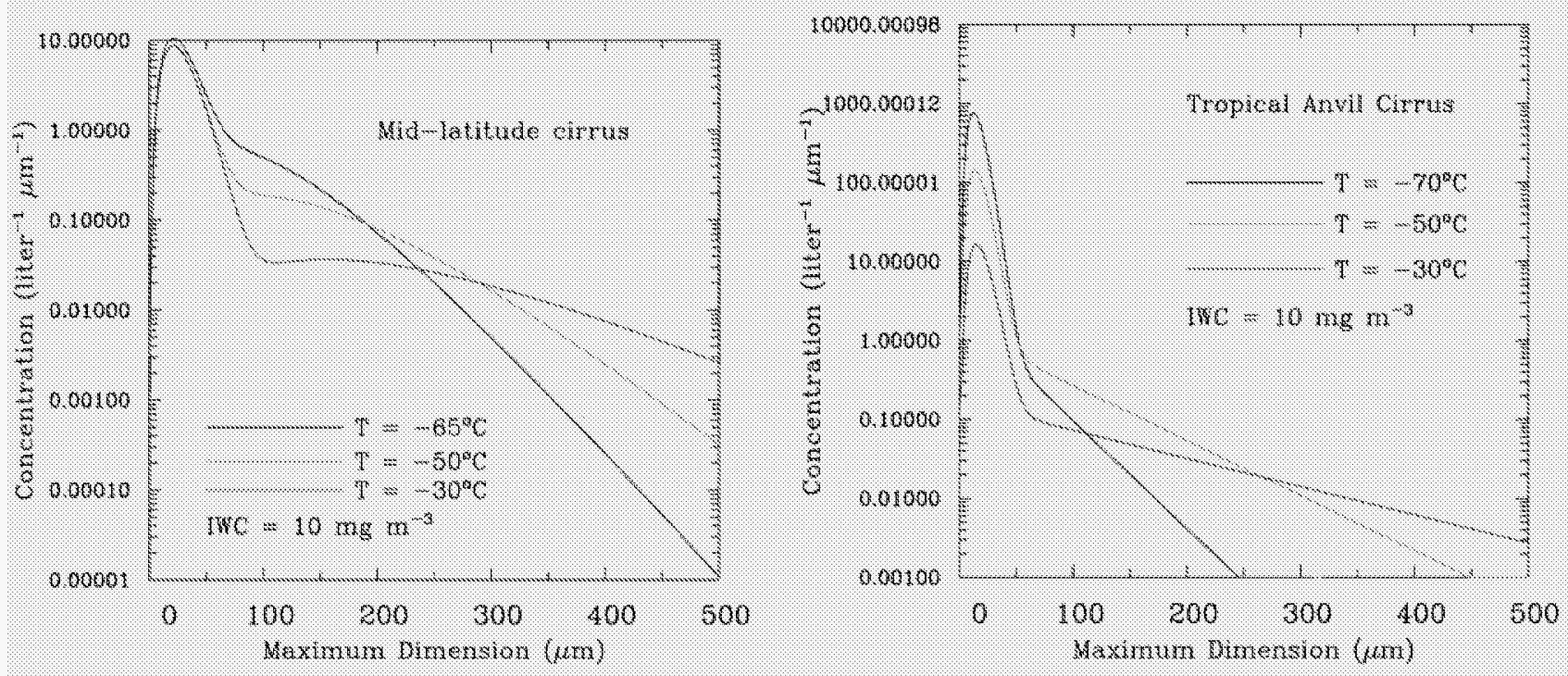

Figure 1. Examples of PSD from the mid-latitude cirrus and the tropical anvil cirrus schemes, which are diagnosed as a function of temperature and IWC.
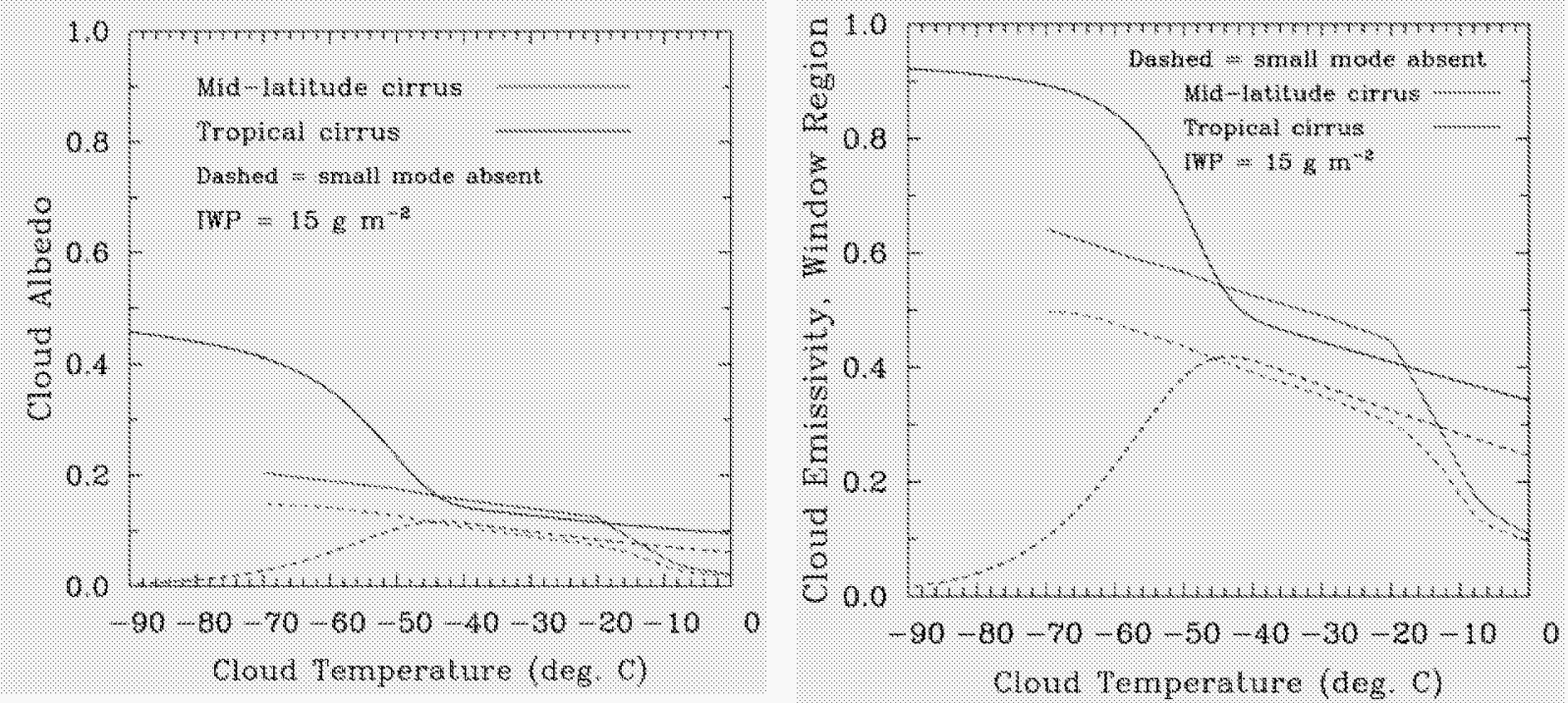

Figure 2. Albedo and emissivity differences between mid-latitude and tropical anvil cirrus clouds having the same ice water path (IWP). Note the contribution of the small crystal mode (dashed curves are for the large mode only; solid curves are for the complete PSD). 
4. Treatment of ice particle terminal velocities

The treatment of ice particle terminal velocities $\left(\mathrm{v}_{\mathrm{t}}\right)$ are based on Mitchell (1996), where projected area- and mass-dimensional power laws are used to calculate $\mathrm{v}_{\mathrm{t}}$ for any ice particle shape. The methodology for determining ice mass sedimentation rates for any bimodal PSD is given in Ivanova et al. (2001). The calculation of $\mathrm{v}_{\mathrm{t}}$ for aggregates was improved upon in Mitchell and Heymsfield (2005), which is based on Mitchell (1996) and Khvorostyanov and Curry (2002). These treatments of $\mathrm{v}_{\mathrm{t}}$ and ice mass sedimentation rates apply to any shape and size of ice particle (e.g. small mode ice crystals ("cloud ice"), large mode ice crystals, aggregates, graupel and hail), with predicted and observed $\mathrm{v}_{\mathrm{t}}$ differing by less than $20 \%$.

\section{Testing a treatment of ice cloud radiative properties}

Under the previous project, a completely new approach to predicting absorption and extinction in cirrus clouds was developed, now known as the modified anomalous diffraction approximation (MADA). Also, a means of parameterizing the asymmetry parameter "g" for ice clouds in terms of the PSD, wavelength and ice particle shape was developed in collaboration with Dr. Andreas Macke. MADA combined with this g parameterization predicts radiation transfer through ice clouds, and this can be used in GCMs to help predict the radiative feedback from cirrus clouds to the warming induced by greenhouse gases. The first version of MADA, including this parameterization for $\mathrm{g}$, is described in Mitchell et al. (1996), while the final formulation of MADA applied to liquid water clouds is described in Mitchell (2000). A complete description of MADA for ice clouds is given in Mitchell (2002).

The MADA scheme, if sufficiently accurate, would provide for an explicit coupling between ice cloud microphysics and cloud-radiation interactions. This is possible by noting that absorption and extinction are completely defined by knowledge of the cloud particle masses and projected area. While conserving these two properties, the physical PSD is transformed into a PSD of equivalent photon path spheres. The photon path is simply the particle volume (mass/bulk density of ice) divided by its projected area, and it governs the absorption and the scattering processes. It is the same principle that the "effective radius" concept is based on, although MADA produces a PSD of equivalent photon path spheres rather than a single effective radius. Using a single effective radius or diameter to describe the radiative properties of cirrus cloud PSD can lead to large errors (Mitchell 2002), whereas the MADA approach does not since the PSD shape is preserved. MADA is formulated in terms of the bimodal PSD shape (i.e. PSD parameters) and ice particle shape (projected area- and mass-dimensional relationships), and can treat any combination of ice particle shapes in each PSD mode. Thus it provides for an explicit coupling between the cloud microphysics and radiation.

This project tested the MADA scheme (which predicts absorption and extinction efficiencies for single crystals as well as the PSD) against similar calculations from exact electrodynamic theory, namely, a new formulation of T-matrix theory and the Finite Difference Time Domain (FDTD) method. This testing proceeded over a wavelength range of 1.85-18 $\mu \mathrm{m}$ regarding Tmatrix and 3-100 $\mu \mathrm{m}$ regarding the FDTD method. The testing with T-matrix was based on a PSD from a laboratory grown ice cloud, and extinction measurements were also made for this cloud, so that MADA was tested against extinction measurements and T-matrix theory based on 
the same ice cloud. The FDTD-MADA comparisons were made for the ice particle shapes shown in Fig. 3 using several bimodal PSD in each case, and an example of such a comparison is given in Fig. 4. The PSD was sufficiently narrow (i.e. small crystal sizes) so that the FDTD scheme yielded accurate results. Assuming that the calculations from exact theory are correct, MADA errors were always less than $15 \%$ at any given wavelength regarding the T-matrix and FDTD comparisons, with average errors around 6\%. These results are reported in Mitchell et al. (2005).

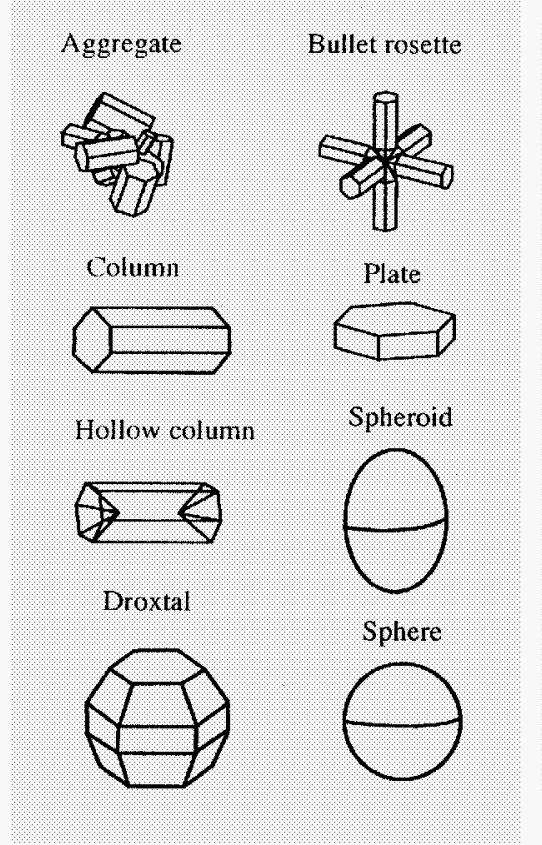

Figure 3. Ice crystal shapes used in FDTD-MADA comparisons.

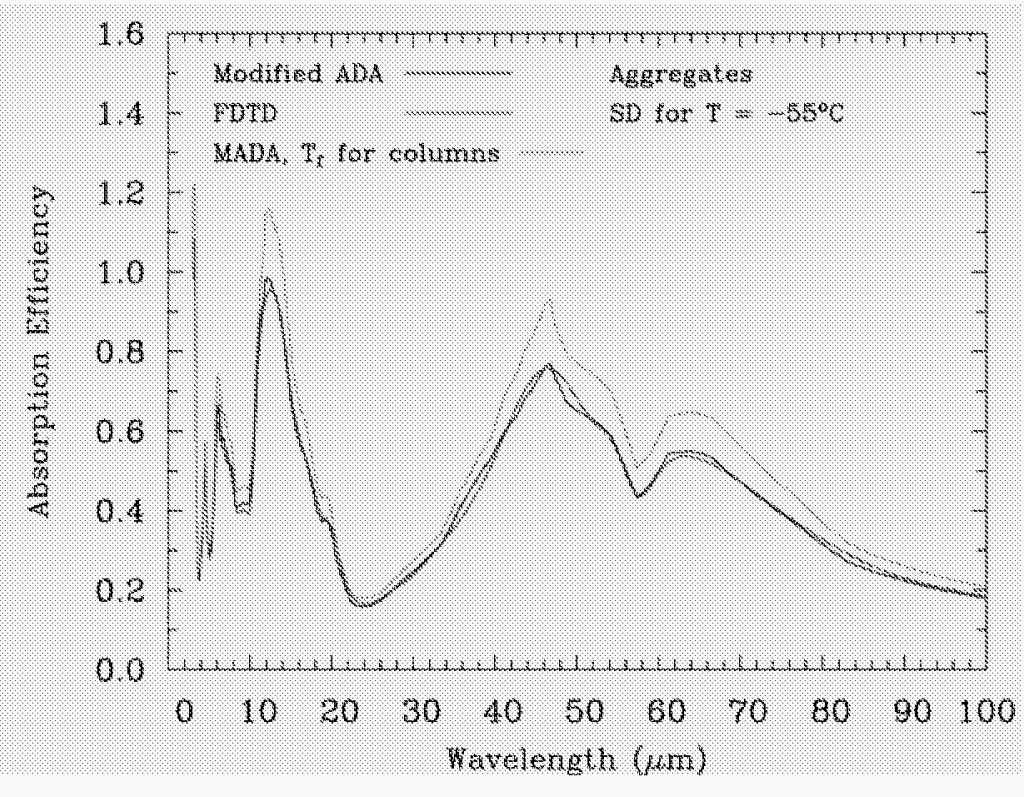

Figure 4. Comparison of MADA with FDTD for aggregates. The green curve uses the tunneling factor for hexagonal columns, an implicit assumption in most schemes of ice optical properties.

The MADA scheme differs from other schemes of ice cloud optical properties in that it parameterizes the processes governing scattering and absorption of radiation. Other schemes treat the optical properties of single crystals with a combination of exact theory and an approximation in regions where exact theory does not apply, and then translate these single particle results to the cloud microphysics by representing the PSD as an effective diameter, $D_{e}$. That is, extinction, absorption and $g$ are related to $D_{e}$ via curve fits, where these radiative properties were calculated from PSDs corresponding to $D_{e}$. The problem with this approach is that two PSDs may have the same $D_{\mathrm{e}}$ but significantly different radiative properties (Mitchell 2002).

One of the processes parameterized in MADA is known as photon tunneling, and it accounts for absorption and scattering of radiation beyond the physical cross-section of the particle. Although the general behavior of this process as a function of size parameter $(\pi \mathrm{D} / \lambda, \lambda=$ wavelength) and ice refractive index appears to be adequately described in MADA, the 
magnitude of the tunneling process, quantified by the tunneling factor $\mathrm{T}_{\mathrm{f}}$, was not known for ice crystals. Fortunately, the conventional approach described above can be used with MADA to solve for $T_{f}$. This was done for the ice particle shapes shown in Fig. 3. Since $T_{f}$ is the only free parameter in MADA, $\mathrm{T}_{\mathrm{f}}$ can be solved for by comparing MADA with an accurate solution (e.g. FDTD) and choosing a $T_{f}$ to maximize agreement between the exact solution and the MADA solution. This was done in Fig. 4 , where $T_{f}=0.3$ for aggregates. The green curve in Fig. 4 is the MADA solution for aggregates but using a $\mathrm{T}_{\mathrm{f}}$ of 0.80 , corresponding to hexagonal columns. Since conventional schemes of ice cloud optical properties are usually based on hexagonal columns, a $T_{f}$ of 0.80 is implicit in the optical properties predicted. But if the true $T_{f}$ for a PSD was 0.3 (as in the case of aggregates or irregular shaped ice particles), then errors from the conventional schemes would be on the order of 10-20\%, as shown by the green curve in Fig. 4 .

The MADA scheme now includes a parameterization for $T_{f}$ in terms of ice crystal shape and aspect ratio (length-to-width ratio). Any type of bimodal size distribution (expressed as gamma functions) and any combination of ice crystal shapes for each mode of the PSD can be assumed with MADA. In addition, MADA is analytically formulated requiring negligible computer time to run; it is now being used in real-time for operational satellite retrievals (http://www.aer.com/cloud/). The above findings are reported in Mitchell et al. (2005).

Finally, MADA and the ice sedimentation scheme require knowledge of the relative abundance of ice particle shapes found in cirrus clouds. Dr. Paul Lawson of SPEC Inc. has provided us with a temperature-dependent "recipe" of ice particle shape, based on 21 flights in mid-latitude cirrus clouds using his Cloud Particle Imager (CPI). He will provide us with a similar recipe for tropical cirrus clouds in the near future. The tropical crystal shape recipe we are currently using is based on limited observations of tropical anvil cirrus reported in the literature.

\section{GCM experiments}

Although not a task in this project, the above project deliverables (PSD schemes, fall velocity scheme and MADA) are being tested in the Community Atmospheric Model (CAM), part of the Community Climate Systems Model (CCSM) developed at the National Center for Atmospheric Research (NCAR). The CCSM is a public domain, state-of-the-art GCM that is used world-wide by the academic and research community. Some initial results from these CAM experiments are reported here to demonstrate how this project has revealed the importance of cirrus PSD in climate simulations and how it has lead to improvements in the CAM. These CAM experiments were funded by the National Science Foundation (NSF).

Figure 5 illustrates fall velocities predicted for the median mass dimension of the PSD, which is representative of the overall ice mass

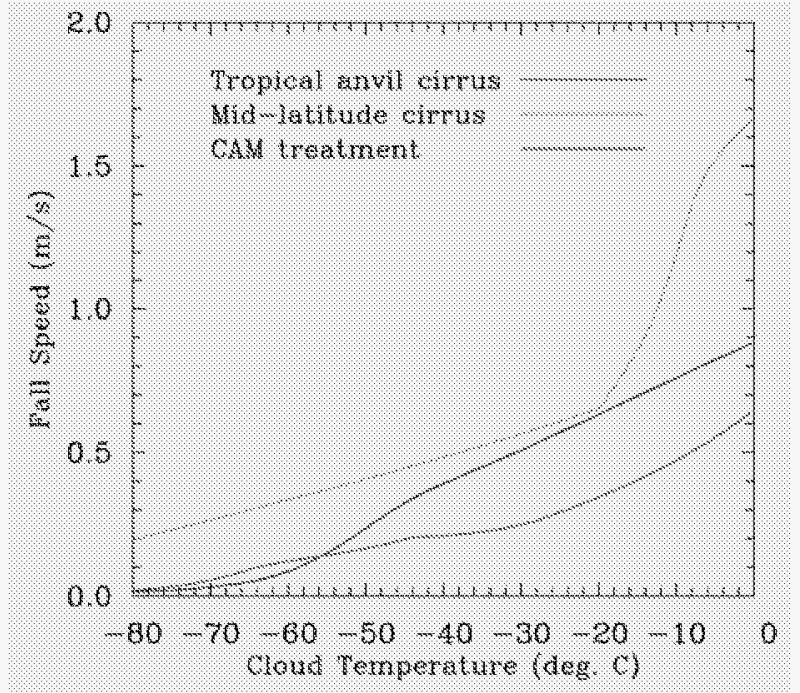

Figure 5. Comparison of ice mass sedimentation rates for tropical anvil and mid-latitude cirrus clouds, and the sedimentation rates currently predicted by predicted by the CAM. sedimentation rate. This is shown for PSD-temperature relationship predicted by the tropical anvil scheme and the mid-latitude scheme, as well as the $D_{e}$-temperature scheme currently used in the CAM. While the tropical anvil and mid-latitude PSD schemes use the fall velocity 
scheme of Mitchell and Heymsfield (2005) noted above, the CAM $D_{e}$ scheme is based on a fall velocity parameterization developed at NCAR which is not sufficiently based on the physics of fluid dynamics. That is, the NCAR fall velocity scheme appears too insensitive to particle size relative to more theoretically rigorous treatments described in the literature (e.g. Mitchell 1996, Heymsfield and Iaquinta 2000, Heymsfield 2003, Mitchell and Heymsfield 2005).

The different behavior of the tropical anvil PSD relative to the mid-latitude PSD scheme is responsible for the fall speed differences in Fig. 5 regarding the tropical anvil and midlatitude cirrus. The amplitude of the small crystal mode increases with decreasing temperature in tropical cirrus, whereas the opposite occurs in mid-latitude cirrus. This phenomena produces the large differences in fall velocity between these PSD schemes at low temperatures. These differences result in greater ice water paths (IWP) for tropical anvil cirrus clouds.

\section{a. In-cloud ice water path}

Figure 6 shows CAM results for two 16 month simulations (including 4 months of spin-up time), where one simulation uses the tropical PSD for the entire planet while the other simulation uses only the mid-latitude PSD. Both simulations use the new fall velocity scheme and the MADA based radiation scheme, allowing explicit coupling between microphysics and radiation. Figure 6 shows the in-cloud IWP for the tropical PSD run minus the in-cloud IWP for the midlatitude PSD run. It is seen that in the tropical western Pacific (TWP) and Indian Ocean regions, where deep convection is common, the IWP is about $10-20 \mathrm{~g} \mathrm{~m}^{-2}$ higher in the tropical PSD simulation. Since IWPs for the mid-latitude PSD simulation were typically $10-25 \mathrm{~g} \mathrm{~m}^{-2}$ in this region, this represents an IWP increase on the order of 40-80\% due to lower fall velocities.

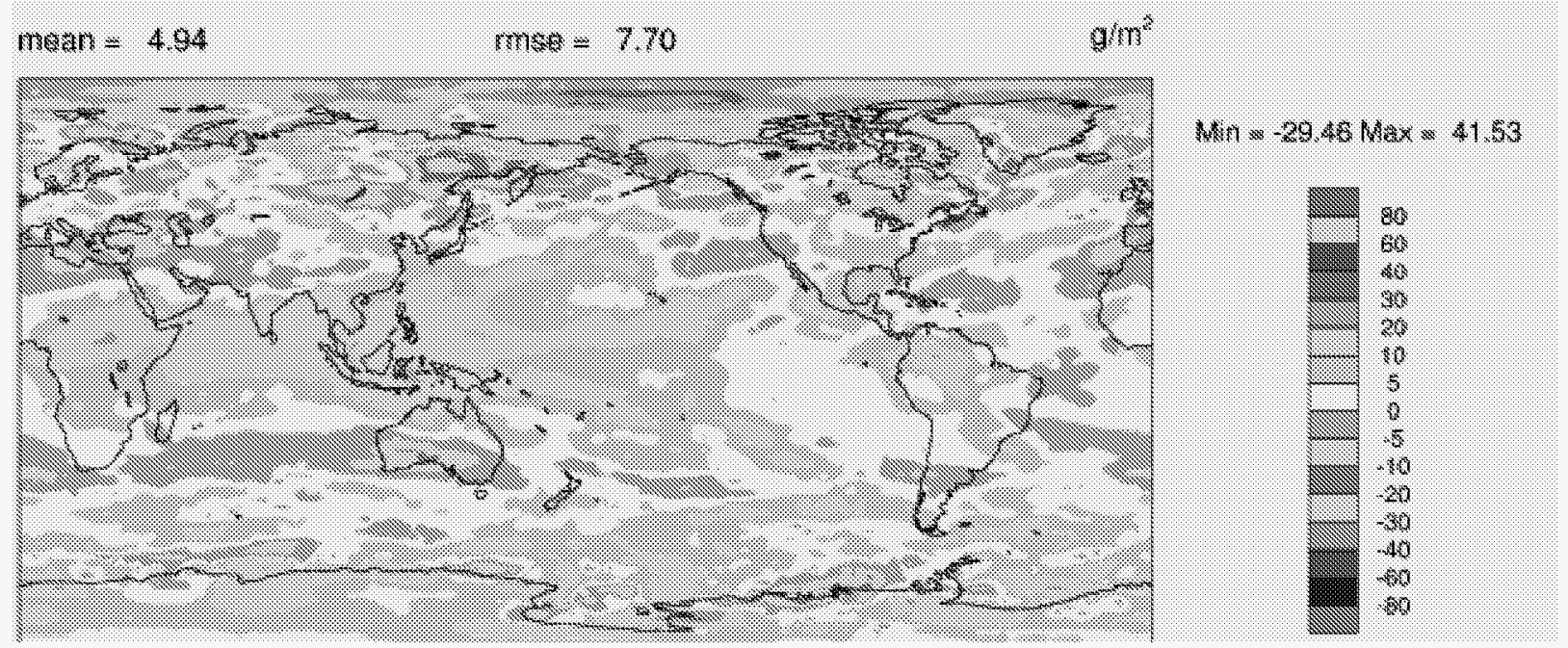

Figure 6. The annual average in-cloud IWP for the tropical PSD run minus the mean in-cloud IWP for the mid-latitude PSD run.

\section{b. Change in cirrus cloud coverage}

The differences in sedimentation rates between the mid-latitude and tropical anvil PSD simulations also produced changes in cirrus cloud coverage. This is shown in Fig. 7, which shows that cirrus cloud coverage increases when the tropical anvil PSD is used, especially in the tropics where the small mode of the PSD can dominate. Zonal annual averages indicate that for the tropical PSD simulation, cirrus coverage increased in the tropics by $7-12 \%$ relative to the 
mid-latitude PSD simulation. This is due to lower sedimentation rates that result in longer cloud lifetimes.

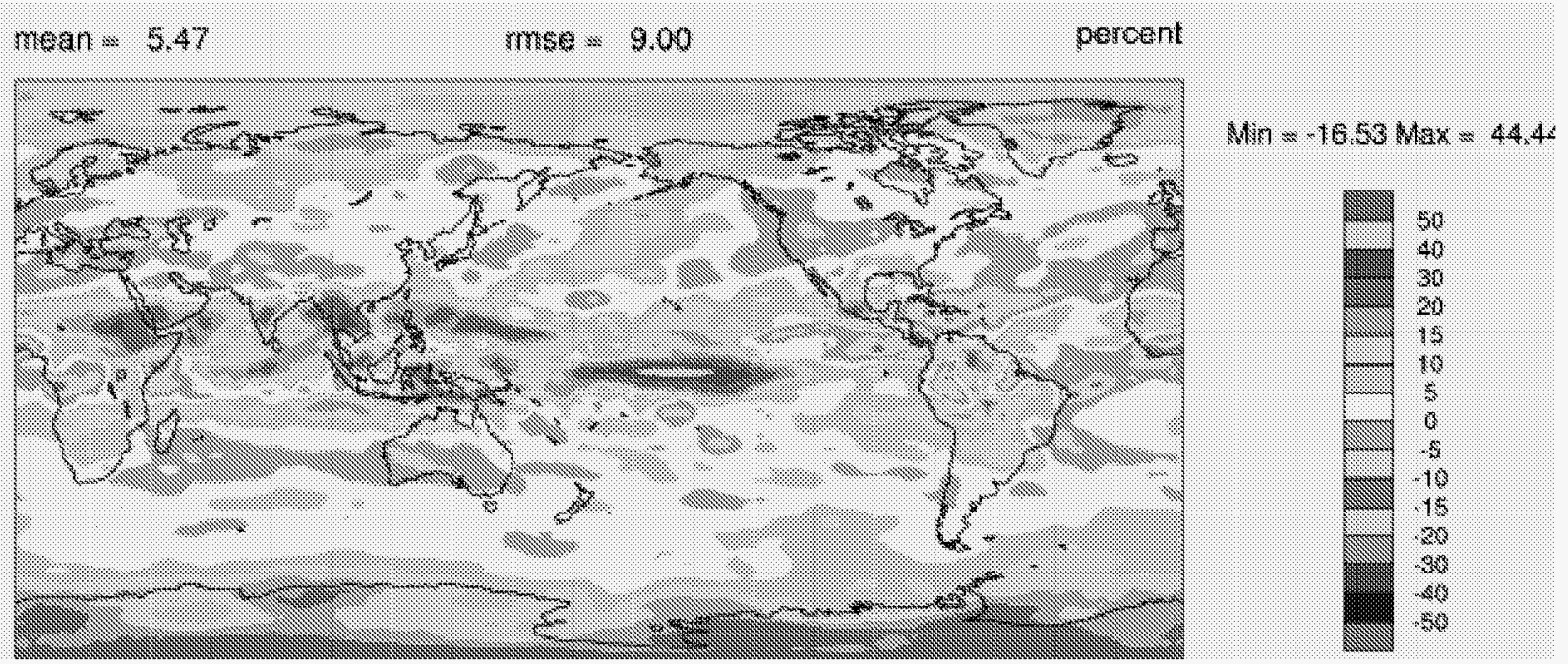

Figure 7. Annual average cirrus cloud coverage for the tropical PSD simulation minus that for the midlatitude PSD simulation, shown as percent difference.

\section{c. Impact on cloud radiative forcing}

Figures 8 and 9 show differences between the two simulations in terms of shortwave cloud forcing (SWCF) and longwave cloud forcing (LWCF), respectively, at the top of the modeled atmosphere. Annual zonal means indicate that SWCF was up to $25 \mathrm{~W} \mathrm{~m}^{-2}$ higher in the tropics with the tropical anvil PSD simulation, and that LWCF was up to $20 \mathrm{~W} \mathrm{~m}^{-2}$ higher in the tropics. For this CAM experiment, the tropical anvil PSD simulation has a net cooling effect in the tropics of about $5 \mathrm{~W} \mathrm{~m}^{-2}$ relative to the mid-latitude PSD run. This is comparable to the net warming directly induced by greenhouse gases in this region. Both the magnitude of these cloud forcing differences and their net effect indicate that the feedback effect of cirrus clouds in response to atmospheric warming by greenhouse gases will be sensitive to the type of PSD scheme used in a GCM. This is a general result applicable to all GCMs that contain realistic coupled parameterizations of ice cloud microphysics and radiation.

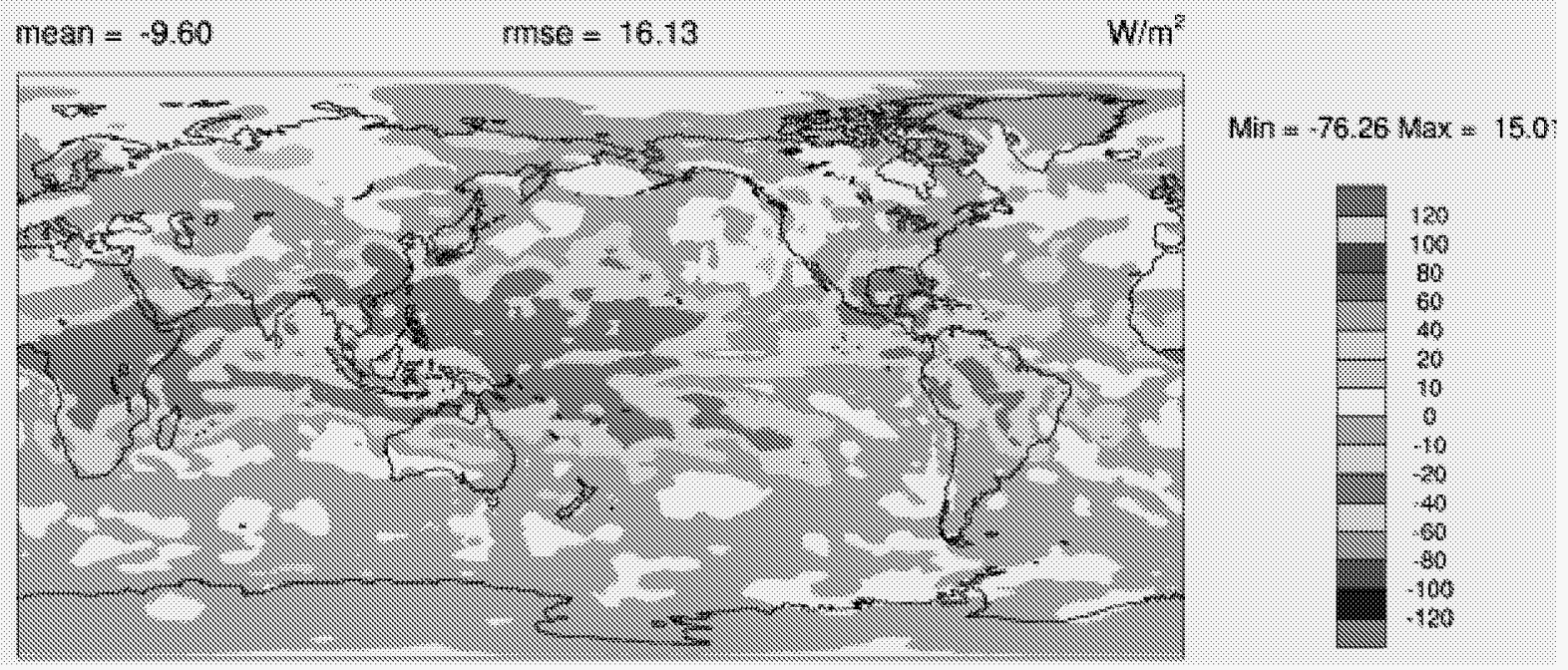

Figure 8. SWCF for the tropical anvil PSD run minus SWCF for the mid-latitude PSD run. 


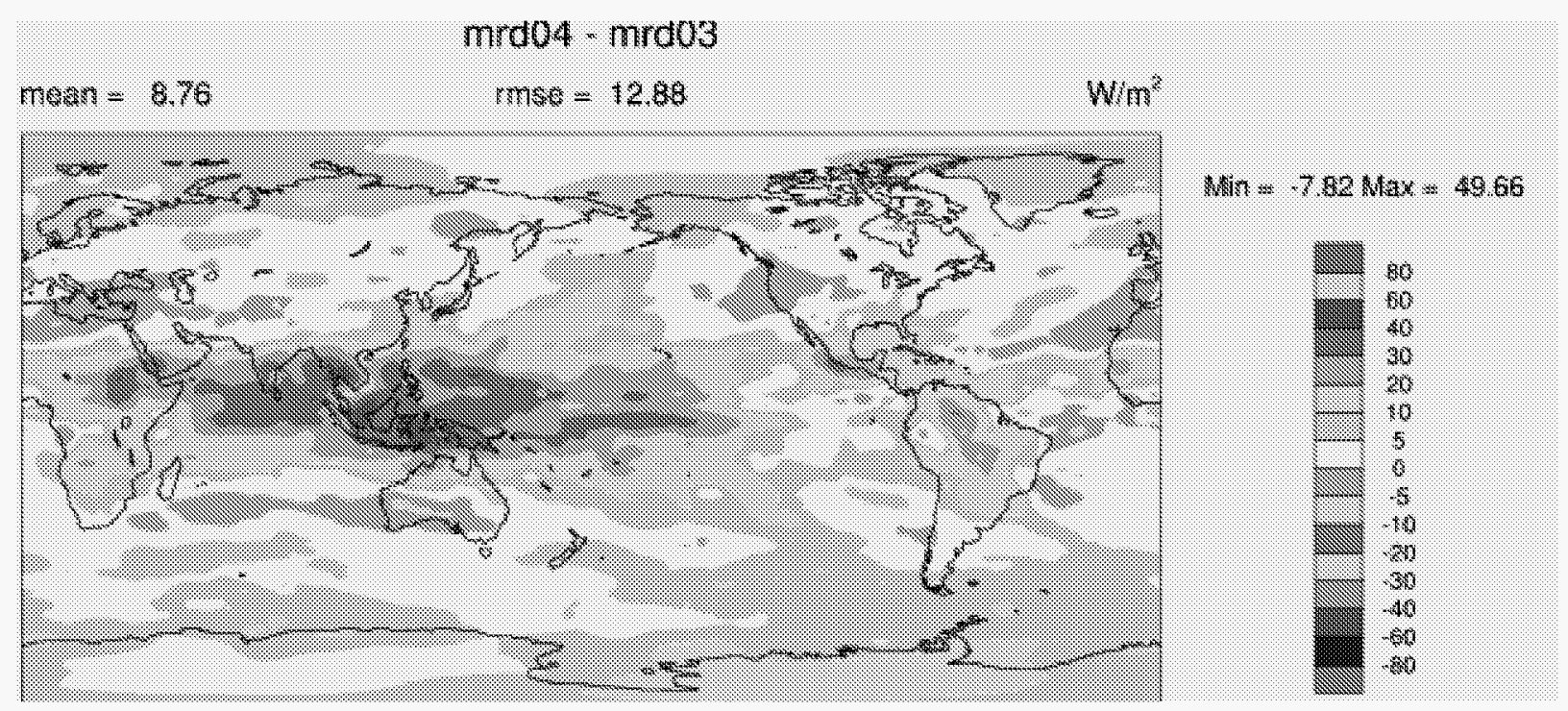

Figure 9. LWCF for the tropical anvil PSD run minus LWCF for the mid-latitude PSD run.

\section{d. Impact on upper troposphere heating rates and temperature}

Shortwave (SW) heating rates are due to absorption of sunlight at near infrared wavelengths, and this absorption depends primarily on the PSD ice water content (IWC). Longwave (LW) cooling rates depend primarily on the projected area of the PSD. Regarding the tropical anvil PSD simulation, the new ice sedimentation scheme increases the IWC the most in the warmer part of the anvil cirrus, and therefore the SW heating rate increases more in that region. In the colder regions near the tropopause, the small mode of the tropical anvil PSD increases the PSD projected area, enhancing LW cooling rates in this region relative to the mid-latitude PSD simulation. Lower in the troposphere cirrus PSD are broader in the tropical scheme, resulting in a reduction in cooling rate. These effects are shown in Fig. 10 for both SW heating and LW cooling rate differences. The $\mathrm{SW}$ heating rate increases range from about 0.05 to $0.15 \mathrm{~K} /$ day, while the LW heating rate increases (i.e. reduction in LW cooling rates) range from about 0.1 to $0.25 \mathrm{~K} /$ day. These heating rate increases combine to produce a temperature increase reaching about $3.5 \mathrm{~K}$ in the tropical upper troposphere, relative to the mid-latitude PSD run. This is a dramatic temperature increase and sensitivity for a region that can strongly influence deep convection and the general circulation. The region of this temperature increase is underpredicted with respect to temperature by most GCMs, and is known as the "cold bias". These results suggest that the tropical upper troposphere cold bias common to many GCMs may be remedied by an appropriate choice of the PSD scheme.
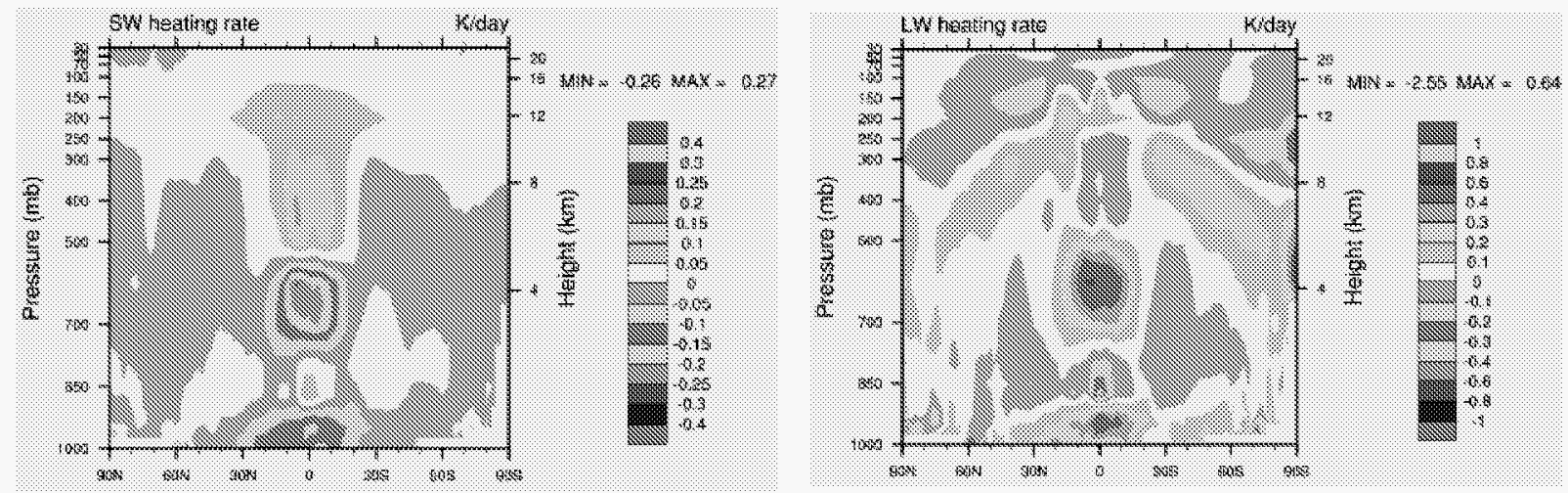

Figure 10. Shortwave and longwave heating/cooling rate differences (tropical - mid-lat. PSD runs). 

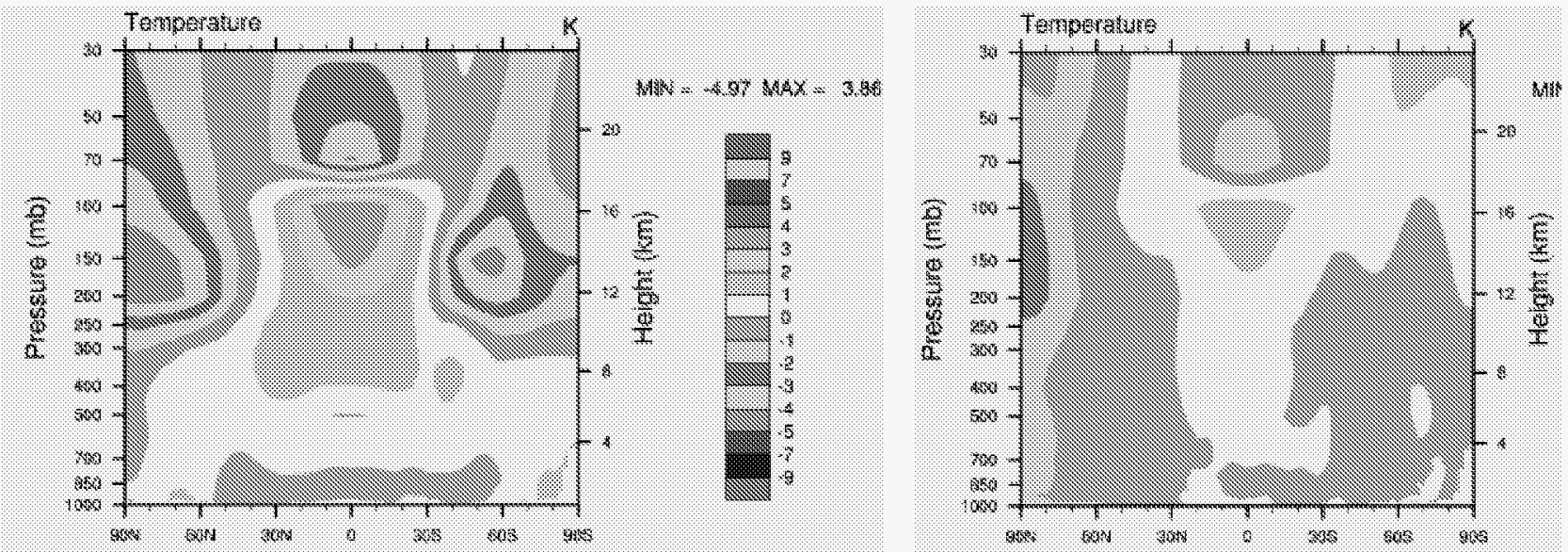

Figure 11. Left panel: Temperature differences between tropical anvil and mid-latitude PSD simulations. Right panel: Temperature difference between the tropical anvil PSD and the standard CAM simulation.

\section{e. Improvements to the CAM}

CAM experiments are currently underway for testing the tropical and mid-latitude PSD schemes (and associated ice sedimentation and radiation schemes), including algorithms for identifying tropical anvil vs. mid-latitude ice clouds. However, some insight can be gained at this early stage by comparing the tropical anvil PSD simulation against a parallel run using the standard CAM configuration (e.g. standard CAM microphysics and radiation). Differences in SWCF and LWCF (not shown) were small (except CAM SWCF was significantly lower in magnitude in the tropics), and SW heating rates were about $0.05-0.15^{\circ} \mathrm{K} /$ day greater in the CAM run while $\mathrm{LW}$ heating rates (i.e. reduction in $\mathrm{LW}$ cooling rates) were about $0.1-0.3^{\circ} \mathrm{K} / \mathrm{day}$ greater in the tropical anvil PSD run. The reasons for this primarily stem from (1) the ice optical properties used in the CAM (Ebert and Curry 1992) and (2) the fall velocity/ice sedimentation scheme used in the CAM. Neither (1) or (2) were found to behave in accord with more recent schemes that appear to be based on better physics. The right panel of Fig. 11 shows that the tropical upper troposphere is warmer by about $1.5^{\circ} \mathrm{C}$ in the tropical anvil PSD run than in the CAM control run as a result of the heating rate differences noted above. This is good news for the CAM, since the CAM has a cold bias in this region of about $2{ }^{\circ} \mathrm{C}$. Given that the vast majority of cirrus clouds found in the tropics will be diagnosed as tropical anvil cirrus in the new version of the CAM, this result indicates that the new ice cloud microphysics/radiation schemes will improve the CAM's performance by largely reducing the CAM's cold bias.

\section{f. An indirect aerosol effect for cirrus clouds?}

The nucleation of new ice crystals will affect only the small mode of the PSD, and as they grow to larger sizes some may enter the large mode. The above results indicate that the amplitude of the small mode has a strong influence on the in-cloud heating rates. Since higher ice crystal nucleation rates will increase the amplitude of the small mode, it stands that higher nucleation rates will also affect heating rates in the upper troposphere where cirrus reside. 
Recent observations (Santer et al. 2003a; 2004) show that the height of the tropopause (defined as the temperature trend reversal between the troposphere and stratosphere) has increased by about 200 meters since 1979, and this height increase has been predicted in GCM simulations (Santer et al. 2003b; 2004) to result primarily from well-mixed greenhouse gases (warming of the troposphere) and stratospheric ozone depletion (cooling of the stratosphere). Patterns of tropopause height change, taken from Santer et al. (2003b), are shown in Fig. 12 for two observational data sets using reanalysis data and for a GCM simulation (panel C) that includes forcing from greenhouse gases, ozone, sulfate aerosol, volcanic aerosol and solar irradiance.

A

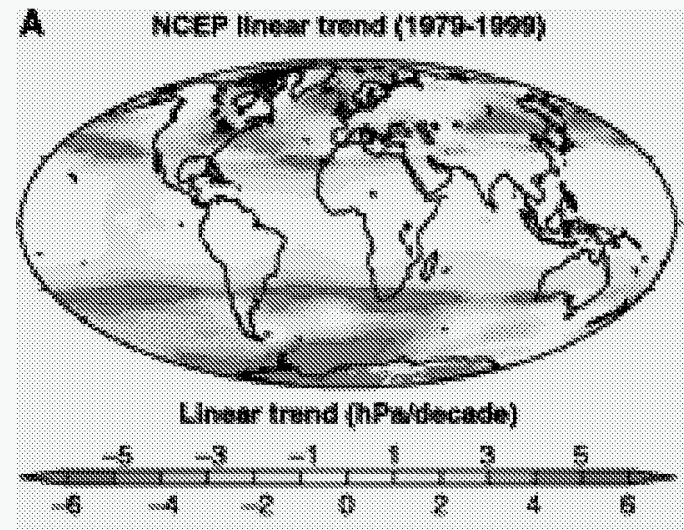

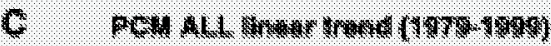

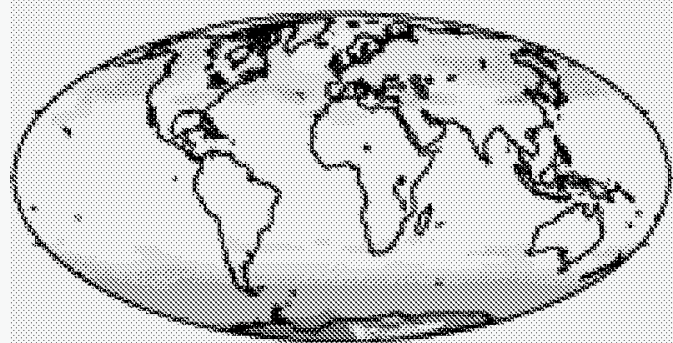

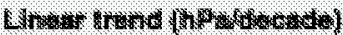

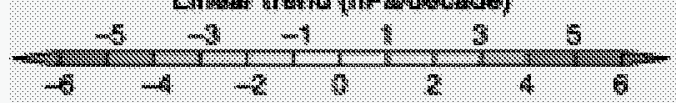

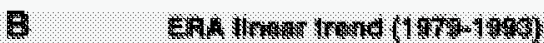

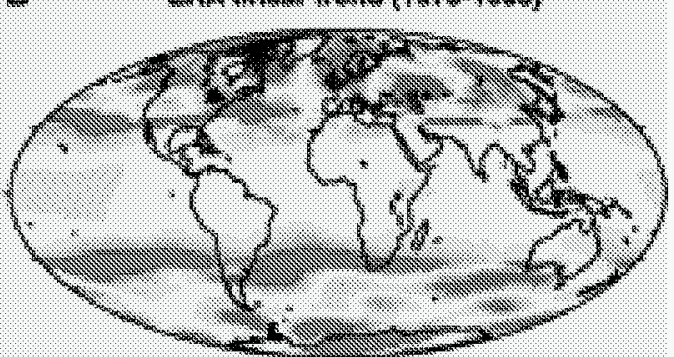

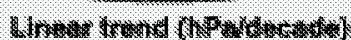

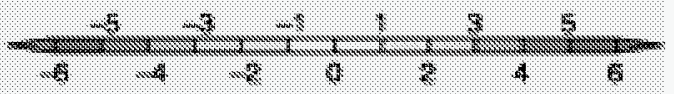

D

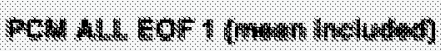

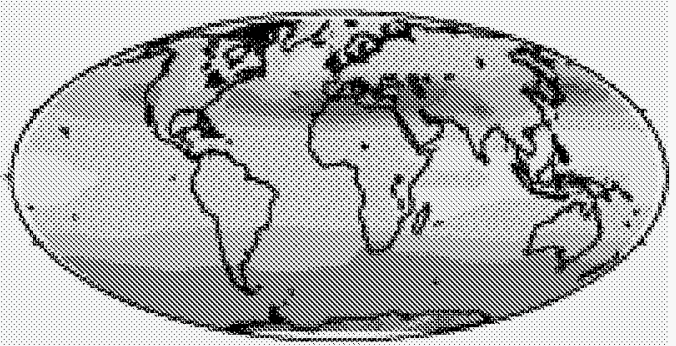

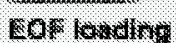

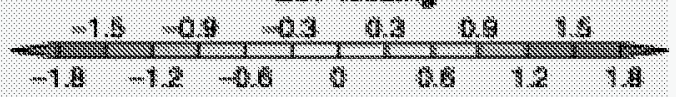

Figure 12. Taken from Santer et al. (2003b), showing the least-squares linear trends in tropopause height change ( $\mathrm{mb}$ /decade) for two reanalysis data sets based on weather balloon observations; the reanalysis from the National Center for Environmental Prediction (NCEP; panel A) and the European Center for Medium-Range Weather Forecasting (ECMWF, or ERA, in panel B). The NCEP and ECMWF data sets are based on the periods 1979-1999 and 1979-1993, respectively. Differences between panel A and $B$ were attributed to the shorter sampling period for panel $B$. Panel $C$ shows the GCM simulated rate of change in tropopause height in $\mathrm{mb} /$ decade, which can be compared directly with panels $A$ and $B$.

The Department of Energy Parallel Climate Model (PCM) GCM was used to simulate the tropopause height changes. From Fig. 12 it is seen that the PCM prediction in panel $\mathrm{C}$ captures the basic trend of observed height changes, but it does not capture the pattern of tropopause height changes in the mid-latitudes, and the trends in height change may be underestimated somewhat. Thus, there appears to be a possibility that something else, in addition to greenhouse gases and ozone, is also acting to increase tropopause heights. This "something else" may be mid-latitude cirrus clouds in the vicinity of the tropopause. 
As described in Section 6d, cirrus heating rates are largely governed by the behavior of the small mode of the PSD. If ice crystal nucleation rates are increasing as a result of higher aerosol particle concentrations, then the enhancement to the small mode will be minor in a relative sense for tropical anvil cirrus, since the small mode amplitude is largest at the coldest temperatures. Conversely, in mid-latitude cirrus, the small mode amplitude is minimized at the coldest temperatures (i.e. near the tropopause). It is for this reason that mid-latitude cirrus near the tropopause should be susceptible to heating rate changes resulting from anomalously high nucleation rates. That is, higher nucleation rates resulting from intrusions of higher aerosol concentrations will likely produce a significant increase in the small mode amplitude, resulting in a significant change in heating rates near the tropopause in the mid-latitudes. The left panel in Fig. 11 shows that the difference in PSD schemes (tropical - mid-latitude) at mid-latitudes and in the polar regions enhances the temperature gradient in the upper troposphere/lower stratosphere, but without the warming in the upper troposphere. This appears to be related to an enhancement in LW cooling rates in the upper troposphere (just below the tropopause) regarding the tropical PSD scheme. Vertical cross-sections of relative humidity from the CAM output (not shown) indicate that tropopause heights at mid-latitudes were increased by the tropical PSD scheme, indicating that the introduction of higher concentrations of small mode ice crystals will raise tropopause heights there.

The observed spatial pattern of elevated tropopause height in Fig. 12 is consistent with the above mechanism, with lower height increases in the tropics and relatively large height increases in the mid-latitudes. In Fig. 2 of Santer et al. (2004), an improved ERA dataset having 60 levels reveals that zero or slightly positive increases in tropopause height occurred in the most convective regions of the tropics, coinciding with anvil cirrus. In addition, the observed pattern in the mid-latitudes appears to roughly coincide with regions characterized by cirrus clouds and possibly increasing aerosol concentrations in the upper troposphere.

If this speculation were true, then the observed spatial trends in tropopause height changes, and/or the observed cooling or heating rates in the upper troposphere at mid-latitudes, may be used to estimate changes in the PSD small mode amplitude that are needed to account for these observations. The amplitude of the small mode in the mid-latitude PSD scheme could be arbitrarily adjusted to determine what percentage change in the concentration of small ice crystals would be necessary to explain the observed warming or cooling in the upper troposphere over the period 1979-1999. This adjustment would alter the cirrus radiative properties, and satellite data could be inspected to determine whether such a change in cirrus radiative properties is plausible. This might be a way to infer a cirrus indirect aerosol effect through the expected consequences of such an effect.

\section{Other aspects of the project}

\section{a. Development of an ice cloud microphysical model}

A limitation of using our parameterized bimodal PSDs to calculate ice mass fluxes is that a static PSD is assumed for a given cloud temperature T, whereas in nature, the PSD is evolving over time at a given T level. The parameterized PSD diagnoses an average PSD for a given T. To address the sensitivity of mass sedimentation rates to the time-dependent microphysical evolution at a given T, a cloud model is needed to realistically portray the evolution of the SD 
and associated mass removal rates. A more microphysically realistic cloud model would have other advantages as well, such as better partitioning between the ice and liquid phases in mixed phase clouds.

A new one-dimensional ice particle growth model, or snow growth model (SGM), has been developed, which predicts PSDs from the supersaturation with respect to ice and the ice crystal nucleation rate. We plan to expand this to a 3-D framework in future work. The following attributes make this model unique from other microphysical models:

1) Microphysical processes are represented by parameterizing a single master equation, the ice particle number density equation, and generating conservation equations for the 0 th and $6^{\text {th }}$ moments (i.e. number concentration and radar reflectivity). This insures the processes are coherently interdependent. The two prognostic equations yield the SD slope parameter (a measure of particle size) and the total number concentration $\mathrm{N}$, from which IWC is determined.

2) Ice particle growth rates depend strongly on ice particle shape, as predicted by the new analytical equations.

3) A new approach to ice crystal nucleation will be tested, with nucleation rates a function of supersaturation. Due to (2), nucleation rates are expected to depend considerably on ice crystal shape, since the growth rates determine supersaturation levels. These processes may help explain the observed high concentrations of ice crystals in frontal clouds between about -5 and $-10 \mathrm{deg}$. C, normally attributed to the Hallett-Mossop process.

4) A rigorous treatment of ice particle fall speeds was implemented and interfaced well with microphysical processes.

5) The SGM can be used to improve radar estimates of snowfall rate and amount since it can be initialized using the $\mathrm{dBZ}$ and approximate temperature at the lowest radar echo. In the intermountain West, the lowest radar echo is often 1-2 km above ground level, and the SGM can estimate the evolution of the PSD down to cloud base and below cloud base to the ground, and thus estimate the snowfall rate at ground level.

Some microphysical findings include: (1) The relatively constant mean ice particle size and number concentration typically observed in the lower regions of natural frontal clouds were predicted by the model for the first time. This was largely due to a shut down of the aggregation process, resulting from negligible dispersion in fall speeds for large aggregates; (2) An aggregation efficiency $E_{a}$ around 0.1 appears to produce spectral evolution similar to observations, consistent with laboratory measurements of $\mathrm{E}_{\mathrm{a}}$; (3) the aggregation process often does not have a strong impact on snowfall rates.

This snow growth model is described in the following publication: Mitchell, D.L., A. Huggins, V. Grubisic, 2005: A new snow growth model with application to radar precipitation estimates. Under revision for the ICCP special issue of Atmos. Research. 


\section{b. $\quad$ First estimates of the extent of photon tunneling in natural cirrus}

Photon tunneling often contributes $15-42 \%$ of the absorption when wavelength and particle size are comparable (i.e. longwave radiation). Photon tunneling accounts for radiation beyond the area cross-section of a particle that is either absorbed or scattered outside of the forward diffraction peak. Studies have shown that tunneling contributions decrease as ice particle shape becomes more complex. Since ice particle shapes in natural cirrus tend to be complex relative to the pristine shapes assumed in treatments of ice cloud radiative properties based on electrodynamic theory (i.e. at low size parameter), the contribution of the tunneling process to absorption represents a large uncertainty in terrestrial radiation transfer and in remote sensing.

We have used MADA to quantify the tunneling process in ice clouds by retrieving a tunneling factor, $\mathrm{T}_{\mathrm{f}}$. The value of $\mathrm{T}_{\mathrm{f}}$ ranges from 1.0 (ice or water spheres) to 0 (no tunneling). The retrieval is based on retrievals of absorption optical depth from the AERI instrument (Atmospheric Emitted Radiance Interferometer), using a moderate and a strongly absorbing wavelength. The procedure and results are described in Mitchell et al. (2002; 2003). As a proof of concept study, we have retrieved $\mathrm{T}_{\mathrm{f}}$ from a mid-latitude and a tropical convective cirrus case study, where $\mathrm{T}_{\mathrm{f}}=0.53 \pm 0.18$ and $\mathrm{T}_{\mathrm{f}}=0.74 \pm 0.27$, respectively. These are the first estimates of tunneling contributions found in natural cirrus clouds. We were invited by BAMS to share these results with the broader community, and these findings have been advertised in the AMS Bulletin's Nowcast section "conference notebook", June 2002 issue, "Answering Ice Cloud Questions through Remote Sensing".

\section{c. Remote sensing retrievals of the PSD small crystal mode}

As reported previously, the small crystal mode of the PSD $(\mathrm{D}<100$ microns) can dominate cirrus radiative properties and sedimentation rates at cold temperatures, and its behavior is critical to understanding the role of cirrus in predicting climate change. However, the FSSP measurements of the small crystal mode continue to be controversial due to the potential for shattering of larger ice particles as they impact the rim of the inlet tube of the FSSP. In fact, shattering of larger ice particles ( $D>350$ microns) may affect the measurements of all the probes that measure ice crystals undetected by the $2 \mathrm{DC}$ probe $(\mathrm{D}<70$ microns), including the CPI and the SID (Small Ice Detector; developed in the UK). Thus it is difficult to ascertain for certain that the high concentrations of small crystals are not due (at least in part) to this postulated shattering phenomena.

Since no direct size distribution (SD) measurements have been able to resolve this issue, we have addressed this issue from the angle of remote sensing, either from ground or from satellite. This avoids altogether the issue of whether small ice crystals are artifacts of shattering at the probe inlet. These results are published in the proceedings of the $12^{\text {th }}$ Conference on Satellite Meteorology and Oceanography, Long Beach, California, 2003, and in the $11^{\text {th }}$ Conference on Atmospheric Radiation, Ogden, Utah, 2002 (which was advertised in the AMS Bulletin's Nowcast section "conference notebook", June 2002 issue, "Answering Ice Cloud Questions through Remote Sensing").

The approach is now briefly described. By ratioing the retrieved absorption optical depth (AOD) corresponding to a moderately and strongly absorbing wavelength, the presence of a small ice crystal mode in the cirrus PSD can be evaluated and quantified. This AOD ratio is very 
sensitive to the small mode, since these crystals have much lower absorption efficiencies than large mode crystals. This fact can be exploited by using the modified anomalous diffraction approximation (MADA), which agrees on average within 5\% of exact T-matrix solutions for hexagonal columns. Other ice cloud radiation schemes are generally parameterized in terms of ice water content (IWC) and effective diameter $D_{e}$, with implicit assumptions on PSD shape such as the degree of bimodality. MADA uses explicit microphysical input, such as the bimodal PSD parameters. This allows us to modify the PSD properties and evaluate the amplitude of the small mode, which is responsible for the attenuation of the AOD ratio. Using wavelengths between 3.7 and 4.0 microns provides information on the large mode as well.

Our retrievals of AOD ratios from the AERI (ground-based) and the MODIS instrument reveal surprisingly good agreement with AOD ratios predicted by MADA for two case studies; one tropical anvil case and one mid-latitude case, using the respective PSD scheme. If AOD retrievals continue to validate these two PSD schemes, this would represent a major advancement not only in understanding ice cloud-radiation interactions, but also in our fundamental understanding of cloud physics and ice crystal nucleation.

\section{d. Dependence of spatial distribution of snowfall amount on microphysical parameterization: An MM5 modeling study}

As part of the modeling component of this project, a MM5 sensitivity study was conducted to evaluate the dependence of ice mass removal rates on the microphysical scheme used. This illustrated the importance of accurate ice particle fall velocity information in forecasting snowfall amounts over the Sierra Nevada mountains. This was the topic of a Master's thesis funded by this project.

It was found that the Dudia and Schultz ice schemes dropped considerably more snowfall on the upwind side of the Sierra Nevada mountains than did the Reisner and Goddard Space Flight Center schemes, due to the treatment of the SD evolution and fall velocities. This study has been published in an article in Monthly Weather Review.

\section{Collaborations}

\section{Hadley Centre, U.K. Meteorological Office}

Two PSD parameterizations for tropical and mid-latitude cirrus clouds (Mitchell et al. 2000b; Ivanova et al. 2000) were implimented at the Hadley Centre (UKMO) by Dr. John Edwards. This work was begun during the summer of 1999 when the P.I. worked at the Hadley Centre for one week. Dr. Edwards has developed a means for diagnosing whether large scale cloud in the Unified Model (UM) GCM was of frontal or convective origin. This information is needed to apply these two PSD parameterizations. In brief, potential vorticity gradients must exceed a threshold value for an associated cloud to be diagnosed as frontal. Below this threshold, the cloud is diagnosed as of convective origin. Over the oceans, the criteria for frontal cloud is that the associated sea surface temperature (SST) must be less than $26{ }^{\circ} \mathrm{C}$ and cloud temperature must be warmer than $-60^{\circ} \mathrm{C}$. In practice, potential vorticity gradients are below the chosen threshold value when SSTs exceed $26^{\circ} \mathrm{C}$. Dr. Edwards has completed an initial set of simulations using our radiation and PSD schemes, assuming planar polycrystals. Based on a CEPEX 
microphysics/radiation experiment within and above an anvil cirrus cloud, radiative properties predicted from the observed microphysics matched the observed radiative properties best when the asymmetry parameter $(\mathrm{g})$ for hexagonal columns was used. Therefore our g parameterization for hexagonal columns was used in the UM simulations.

One year simulations have been conducted with the UM, and these are described in Edwards et al. (2000). A comprehensive new microphysics scheme was also implemented in the UM (Wilson and Ballard 1999), which uses the ice particle fallspeed formula developed in Mitchell (1996). As stated, ice cloud PSD and associated radiative properties were given by our new parameterizations. These new schemes reduced errors in SWCF and LWCF relative to ERBE observations, and further reduced the upper troposphere cold bias to a mere $-1{ }^{\circ} \mathrm{C}$ relative to the ECMWF reanalysis. However, this new version of the UM could not be run in coupled mode because its net downward radiative flux at the top of the atmosphere is too large and would cause climate drift: it would need to be brightened by $1.5 \mathrm{~W} \mathrm{~m}^{-2}$.

\section{Scripps Institute of Oceanography}

We have continued to collaborate with Drs. Richard Somerville and Sam Iacobellis at Scripps Institute of Oceanography on representing cirrus clouds in their Single Column Model (SCM). An SCM models a domain about the size of a GCM grid cell, and the Scripps SCM was updated at the domain boundaries with measurements from the ARM SGP site. In this way the SCM can be used to test various parameterizations of physical processes.

The Scripps collaboration resulted in the paper "On the Sensitivity of Radiative Fluxes to Parameterized Cloud Microphysics", and is published in the Journal of Climate. The effective diameter $\left(D_{c}\right)$ and ice sedimentation parameterization developed under this project, as well as MADA, were incorporated into the Scripps Single Column Model (SCM), and compared with other radiation and $\mathrm{D}_{\mathrm{e}}$ schemes, as well as ARM retrievals of $D_{e}$ using the radar-AERI method. A key finding was that all 4 of the $D_{e}$ parameterizations tested gave $D_{e}$ values considerably less than the retrieved $D_{e}$ values. It was suggested that this is due to the radar-based retrieval not "seeing" the small ice crystal mode of the SD, resulting in a larger $D_{e}$ value than would be obtained had the entire SD been sampled. In Ivanova et al. (2001), it was shown that ignoring the small mode would increase $\mathrm{D}_{\mathrm{e}}$ by about $45 \%$. It was found that variations in ice particle fall speed due to changes in crystal shape produced significant changes in ice mass sedimentation rates and associated cloud feedbacks. These variations translated to outgoing longwave radiation (OLR) variations of $4 \mathrm{~W} \mathrm{~m}^{-2}$. These variations may have been larger if the fall velocities were based on the actual ice particle shape comprising the PSD, and not the corresponding $\mathrm{D}_{e}$ value of the PSD.

\section{Laboratoire de Meteorlogie Dynamique, France}

We have collaborated with Dr. Claudia Stubenrauch and Gaby Radel at Laboratoire de Meteorologie Dynamique, Ecole Polytechnique, France, in their work on satellite retrievals of cirrus cloud effective diameter, $\mathrm{D}_{\mathrm{e}}$. This French collaboration resulted in the paper "Retrieval of Effective Ice Crystal Size in the Infrared: Sensitivity Study and Global Measurements from TIROS-N Operational Vertical Sounder Observations", published in the Journal of Geophysical Research. This paper used MADA developed under this project to retrieve $D_{e}$, and to evaluate the sensitivity of the $D_{e}$ retrievals to various uncertainties in the retrieval process. The PI has worked extensively with this group on this study. 
9. Publications

\section{A. Journal Articles resulting from this project}

Mitchell, D.L., and R.P. d'Entremont, 2000: Nighttime retrieval of ice water path. Proceedings (peer reviewed), 5th Conference on Electromagnetic and Light Scattering by Nonspherical Particles: Theory, Measurements and Applications, AMS, August 28 - September 1, 2000, Halifax, Nova Scotia, Canada.

Mitchell, D.L., W. P. Arnott and C. Schmitt, A.J. Baran, S. Havemann, and Q. Fu, 2001: Contributions of photon tunneling to extinction in laboratory grown hexagonal columns. $J$. Quant. Spectrosc. Radiat. Transfer, 70, 761-776.

Ivanova, D.C., D.L. Mitchell, W.P. Arnott and M. Poellot, 2001: A GCM parameterization for bimodal size spectra and ice mass removal rates in mid-latitude cirrus clouds. Atmos. Res., 59, 89-113.

Mitchell, D.L., 2002: Effective diameter in radiation transfer: General definition, applications and limitations. J. Atmos. Sci., 59, 2330-2346.

Iacobellis, S.F., G.M. McFarquhar, D.L. Mitchell, and R.C.J. Somerville, 2002: On the sensitivity of radiative fluxes to parameterized cloud microphysics. J. Climate, 16, 29792996.

Radel, G., C. J. Stubenrauch, R. Holz and D.L. Mitchell, 2003: Retrieval of effective ice crystal size in the infrared: Sensitivity study and global measurements from TIROS-N Operational Vertical Sounder observations. J. Geophys. Res., 108, No. D9, 4281, doi:10.1029/2002JD002801

Mitchell, D. L., and A. J. Heymsfield, 2005: Refinements in the treatment of ice particle terminal velocity, highlighting aggregates. J. Atmos. Sci., 62, 1637-1644.

Mitchell, D.L., A. Huggins and V. Grubisic, 2005: A new snow growth model with application to radar precipitation estimates. Under review for the ICCP Special Issue of Atmospheric Research.

Grubisic, V., R. K. Vellore, and A. W. Huggins, 2005: Quantitative precipitation forecasting of wintertime storms in the Sierra Nevada: Sensitivity to the microphysical parameterization and horizontal resolution. Mon. Wea. Rev., In Press. 


\section{B. Conference articles resulting from this project}

Ivanova, D., D.L. Mitchell, W.P. Arnott and M. Poellot, 2000: A GCM parameterization of bimodal size spectra for mid-latitude cirrus clouds. Preprints, $13^{\text {th }}$ International Conference on Clouds and Precipitation, 14-18 August, Reno, Nevada.

Mitchell, D.L., D. Ivanova, A. Macke and G.M. McFarquhar, 2000: A GCM parameterization of bimodal size spectra for ice clouds. Proceedings of the $9^{\text {th }}$ ARM Science Team Meeting, March 22-26, 1999, San Antonio Texas.

Mitchell, D.L., W. P. Arnott and C. Schmitt, 2000: Photon tunneling contributions for laboratory grown hexagonal columns. Proceedings, 5th Conference on Electromagnetic and Light Scattering by Nonspherical Particles: Theory, Measurements, and Applications, AMS, August 28 - September 1, 2000, Halifax, Nova Scotia, Canada.

Mitchell, D.L., R.P. d'Entremont, D.H. DeSlover, and W.P. Arnott, 2002: Multispectral thermal retrievals of size distribution shape, effective size, ice water path and photon tunneling contribution. $11^{\text {th }}$ Conf. On Atmos. Radiation, 3-7 June 2002, Ogden, Utah, J13-J16.

Mitchell, D.L., and A.J. Baran, 2002: Testing and comparing the modified anomalous diffraction approximation. Preprints, $11^{\text {th }}$ Conference on Atmospheric Radiation, AMS, 3-7 June 2002, Ogden, Utah, J139-J144.

Mitchell, D.L., R.P. d'Entremont, D.H. DeSlover and W.P. Arnott, 2003: Multispectral thermal retrievals of size distribution shape, effective size, ice water path, optical depth and photon tunneling contribution. $12^{\text {th }}$ Conference on Satellite Meteorology and Oceanography, AMS, Long Beach California, 9-13 February 2003 (available on CD).

Mitchell, D.L., D.H. DeSlover, R.P. d'Entremont, and W.P. Arnott, 2003: Multispectral thermal retrievals of ice water path, effective size and photon tunneling. Preprints, $11^{\text {th }}$ Conference on Atmospheric Radiation, AMS, 3-7 June 2002, Ogden, Utah, J13-J16.

Ivanova, D.C., D.L. Mitchell and G.M. McFarquhar, 2004: Tropical cirrus parameterization for trimodal size spectra. Proceedings, Vol.2, 14th International Conference on Clouds and Precipitation, Bologna, Italy, 19-23 July 2004, 13371339.

Mitchell, D.L., A. Huggins and V. Grubisic, 2005: A new snow growth model with application to radar precipitation estimates. Proceedings, Vol. 1, 14th International Conference on Clouds and Precipitation, Bologna, Italy, 19-23 July 2004, 313-316. 


\section{References cited in this report}

Ebert, E.E., and J.A. Curry, 1992: A parameterization of ice cloud optical properties for climate models. J. Geophys. Res., 97, 3831-3836.

Edwards, J.M., D.L. Mitchell, D. Ivanova and D.R. Wilson, 2000: The sensitivity of the radiation budget to cirrus microphysics: A GCM study. Proceedings of the International Radiation Symposium, St. Petersburg, Russia.

Gayet, J.-F., G. Febvre, and H. Larsen, 1996: The reliability of the PMS FSSP in the presence of small ice crystals. J. Atmos. Oceanic Technol., 13, 1300-1310.

Heymsfield, A.J., and J. Iaquinta, 2000: Cirrus crystal terminal velocities. J. Atmos. Sci., 57, 916936.

Heymsfield, A.J., 2003: Properties of tropical and midlatitude ice cloud particle ensembles. Part I: Median mass diameters and terminal velocities. J. Atmos. Sci., 60, 2573-2591.

Iacobellis, S.F., G.M. McFarquhar, D.L. Mitchell, and R.C.J. Somerville, 2002: On the sensitivity of radiative fluxes to parameterized cloud microphysics. J. Climate, 16, 29792996.

Ivanova, D., D.L. Mitchell, W.P. Arnott and M. Poellot, 2000: A GCM parameterization of bimodal size spectra for mid-latitude cirrus clouds. Preprints, $13^{\text {th }}$ International Conference on Clouds and Precipitation, 14-18 August, Reno, Nevada.

Ivanova, D., D.L. Mitchell, W.P. Arnott and M. Poellot, 2001: A GCM parameterization for bimodal size spectra and ice mass removal rates in mid-latitude cirrus clouds. Atmospheric Research, 59-60, 89-113.

Khvorostyanov, V.I., and J.A. Curry, 2002: Terminal velocities of droplets and crystals: Power laws with continuous parameters over the size spectrum. J. Atmos. Sci., 59, 1872-1884.

Kristjansson, J.E., J.M. Edwards and D.L. Mitchell, 2000: Impact of a new scheme for optical properties of ice crystals on climates of two GCMs. J. Geophys. Res., 105, 10,063-10,079.

Lawson, R.P., B. Baker, B. Pilson and Q. Mo, 2005: In situ observations of the microphysical properties of wave, cirrus and anvil clouds. Part 2: Cirrus clouds. J. Atmos. Sci., In press.

Macke, A., 1993: Scattering of light by polyhedral ice crystals. Appl. Opt., 32, 118-133.

Mitchell, D.L., 1996: Use of mass- and area-dimensional power laws for determining precipitation particle terminal velocities. J. Atmos. Sci., 53, 1710-1723.

Mitchell, D.L., A. Macke, and Y. Liu, 1996: Modeling cirrus clouds. Part II: Treatment of radiative properties. J. Atmos. Sci., 53, 2967-2988. 
Mitchell, D.L., 2000: Parameterization of the Mie Extinction and Absorption Coefficients for Water Clouds. J. Atmos. Sci., 57, 1311-1326.

Mitchell, D.L., D. Ivanova, A. Macke and G.M. McFarquhar, 2000b: A GCM parameterization of bimodal size spectra for ice clouds. Proceedings of the $9^{\text {th }}$ ARM Science Team Meeting, March 22-26, 1999, San Antonio Texas.

Mitchell, D.L., W. Patrick Arnott, C. Schmitt, A.J. Baran, S. Havemann and Q. Fu, 2001: Photon tunneling contributions to extinction for laboratory grown hexagonal columns. J. Quant. Spectroscopy \& Radiation Trans., 70, 761-776.

Mitchell, D.L., 2002: Effective diameter in radiation transfer: General definition, applications and limitations. J. Atmos. Sci, 59, 2330-2346.

Mitchell, D.L., R.P. d'Entremont, D.H. DeSlover, and W.P. Arnott, 2002: Multispectral thermal retrievals of size distribution shape, effective size, ice water path and photon tunneling contribution. $11^{\text {th }}$ Conf. On Atmos. Radiation, 3-7 June 2002, Ogden, Utah, J13-J16.

Mitchell, D.L., R.P. d'Entremont, D.H. DeSlover, and W.P. Arnott, 2003: Multispectral thermal retrievals of size distribution shape, effective size, ice water path and photon tunneling contribution. $12^{\text {th }}$ Conf. On Satellite Meteorology and Oceanography, AMS Annual Meeting, 9-13 February 2003, Long Beach, California (on CD).

Mitchell, D. L., and A. J. Heymsfield, 2005: Refinements in the treatment of ice particle terminal velocity, highlighting aggregates. J. Atmos. Sci., 62, 1637-1644.

Mitchell, D.L., A. Huggins and V. Grubisic, 2005: A new snow growth model with application to radar precipitation estimates. Proceedings, Vol. 1, 14th International Conference on Clouds and Precipitation, Bologna, Italy, 19-23 July 2004, 313-316.

Mitchell, D.L., A. Huggins and V. Grubisic, 2005: A new snow growth model with application to radar precipitation estimates. Under review for the ICCP Special Issue of Atmospheric Research.

Mitchell, D.L., A.J. Baran, W.P. Arnott and C. Schmitt, 2005: Testing and comparing the modified anomalous diffraction approximation. Provisionally accepted for publication in J. Atmos. Sci.

Radel, G., C. J. Stubenrauch, R. Holz and D.L. Mitchell, 2003: Retrieval of effective ice crystal size in the infrared: Sensitivity study and global measurements from TIROS-N Operational Vertical Sounder observations. J. Geophys. Res., 108, No. D9, 4281, doi:10.1029/2002JD002801 
Santer, B.D., et al., 2003a: Behavior of tropopause height and atmospheric temperature in models, reanalysis and observations: Decadal changes. J. Geophys. Res., 108(D1), 4002, doi:10.1029/2002JD002258.

Santer, B.D., et al., 2003b: Contributions of anthropogenic and natural forcing to recent tropopause height changes. Science, 301, 479-483.

Santer, B.D., T. Wigley, A.J. Simmons, P.W. Kallberg, G.A. Kelly, S.M. Uppala, C. Ammann, J.S. Boyle, W. Bruggemann, C. Doutriaux, M. Fiorino, C. Mears, G.A. Meehl, R. Sausen, K.E. Taylor, W.M. Washington, M.F. Wehner, and F.J. Wentz, 2004: Identification of anthropogenic climate change using a second-generation reanalysis. J. Geophys. Res., 109, D21104, doi:10.1029/2004JD005075.

Wilson, D.R., and S.P. Ballard, 1999: A microphysically based precipitation scheme for the U.K. Meteorological Office Unified Model. Q. J. Roy. Meteorol. Soc., 125(557), 1607-1636. 